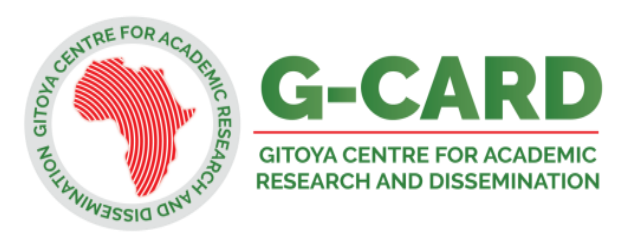

East African Journal of Education and Social Sciences

EAJESS July-September 2021, Vol. 2, No. 3, pp.43-55

ISSN: 2714-2132 (Online), 2714-2183 (Print), Copyright (C) The Author(s)

Published by G-Card

DOI: https://doi.org/10.46606/eajess2021v02i03.0102

URL: http://eajess.ac.tz

\title{
Effect of Practical Work on Physics Learning Effectiveness: A Case of a Senior High School in Ghana
}

\author{
Prof. Victor Antwi, *Nelly Adjoa Sakyi-Hagan, Fortune Addo-Wuver, Bismark Asare \\ University of Education, Winneba \\ *Corresponding Mail: maamekuumah@yahoo.com
}

\begin{abstract}
This study investigated the effect of practical work on students' academic achievement, acquisition of scientific process, skills and attitudes towards the study of selected topics in electricity. Fifty (50) Form Two Physics students from a Senior High Technical School in the Kwaebibirem Municipal of the Eastern Region of Ghana participated in the study. Instruments used to collect data included a student learning evaluation form, questionnaire and pre-and-post-intervention tests. Data was analysed using descriptive statistics and Microsoft Excel 2010 Computer Software. The findings indicated that the students' academic performance were enhanced, they acquired important scientific process skills needed for science practical work and developed positive attitudes towards science practical work. The study recommended that Physics teachers should adopt practical work as a teaching technique and as well be encouraged to teach concepts alongside with practical activities.
\end{abstract}

Keywords: Academic achievement, electricity, scientific process skills, practical work, students' attitude, Physics Learning

\section{Introduction}

Practical work may be considered as engaging the learner in observing or manipulating real or virtual objects and materials. Appropriate practical work enhances learners' experiences, understanding, skills and enjoyment of science and enables them to think and act in a scientific manner. The scientific method is thus emphasized (Millar, 2010). Alkan (2016) propounds that practical work develops problem solving skills and improves conceptual understanding in learners. Students tend to learn better in activity-based courses where they can manipulate equipment and apparatus to gain insight in the content. Millar (2008) suggested that practical work should be viewed as the mechanism by which materials and equipment are carefully and critically brought together to persuade the learner about the veracity and validity of the scientific worldview. If practiced in the right manner from the early secondary school level, critical thinking skills can be attained from practical work in Science, especially, Physics. Practical work puts the students at the center of learning where they can participate in, rather than be told about scientific concepts. Research (Babalola, Lambourne, \& Swithenby, 2020) has proven that if students are to understand the theoretical aspect of Physics taught in the classroom so as to translate them to real life situations, they must master the techniques of practical aspects.

Practical knowledge, according to Duniya (2009), refers to that knowledge that is connected with reality rather than ideas and theories. It could be explained as the knowledge acquired through the practical approach to carrying out scientific investigation and teaching. Mankilik (2011) explains that practical approach means any teaching and learning activity which involves at some point the students in observing or manipulating real objects and materials. It then means that learning of Physics is incomplete without the acquisition of practical knowledge. Physics, according to Josiah (2013), is a practical subject. While students of Physics in secondary schools have found it extremely difficult to perform well in the subject (Al-Rawi, 2013), the development of any nation, which depends on science and technology, hinges on science education.

In Ghana, in spite of the enormous role that Physics provides for national development and the efforts 
of government and other stakeholders in improving science education, Physics results in most certified examinations like the West African Senior School Certificate Examinations (WASSCE) have not been satisfactory. The Chief Examiners' reports from West African Examination Council (WAEC) on science subjects in the Senior High School syllabi of Ghana, over the years, have indicated that students have consistently performed poorly in the practical aspect of the examinations including Physics laboratory practical works (WAEC, 2015; 2016; 2017; 2018; 2019; 2020) since the inception of the Senior High School (SHS) program. According to the reports, most students failed completely or had low grades in Physics more than in any other science subject because they did not perform competently in Paper 2 (practical paper), which usually tests the students' ability to demonstrate the skills needed for laboratory practical work.

Olubu (2005) opined that lack of appropriate apparatus and inability of teachers to improvise hinder effective teaching of science. Many Physics teachers tend to resort to theoretical teaching of the subject, neglecting the practical approach, leading to students having negative perceptions and attitude towards the subject and hence disliking it. According to Masingila and Gathumbi (2012), many science teachers in developing countries are mainly trained in theoretical content aspects, hence their poor handling of Physics practical lessons. The researchers' own experiences with teaching Physics at the senior high school level in Ghana reveal that many students in senior high schools carry out practical work in Physics only towards the end of their studies, that is, in final year. Therefore, these students tend to lack the needed basic experimental techniques, which can only be acquired through regular practical work from the beginning of the senior high school course to the end. It was in the light of this background that the researchers delved into finding out the effect of practical work on student's academic achievement, acquisition of scientific process skills and attitudes towards the study of selected topics in electricity.

The importance of practical work in science is widely accepted and it is acknowledged that good quality practical work promotes the engagement and interest of students and develops a range of skills, science knowledge and academic achievement. However, it appears Physics teachers at the senior high school level have not been able to perform adequate practical work with their students in most of the Physics concepts because they consider it as time-consuming. There is also the problem of lack of equipment and facilities, teacher incompetency and inadequate time allocation, making these teachers resort to the lecture method rather than practical work.

According to the teaching syllabus of Physics (MoESS, 2010), the organization of practical activities is supposed to be carried out continuously and alongside the theory from the beginning of the subject throughout the entire period of study. However, due to the aforementioned factors, practical work in most schools is limited to the final year students who are preparing for their final external practical examinations. Thus, students are virtually not adequately prepared to carry out laboratory experiments before the commencement of their final practical examinations. Consequently, most students are not able to perform competently in the practical paper which is mainly based on skills for practical work. This persistent and alarming development, if not curbed, may lead to decline in scientific and technological manpower needs of the nation. In an attempt to find a solution to this problem, this study was carried out with the aim of investigating the effect of practical work on students' academic achievement, acquisition of important scientific process skills and attitude towards Physics, using selected topics in electricity. The study was guided by the following research questions:

1. How do the academic achievements of students compare, before and after using practical work to teach selected topics in electricity?

2. To what extent does the use of practical work affect students' attitude towards the study of some selected topics in electricity?

\section{Related literature and Studies}

Literature related to this study was reviewed under the headings: Concept of Practical Work, Scientific Process Skills to be developed for Practical Work, Attitude of Students towards Practical-based Teaching and Empirical Studies on Practical Work.

\section{Concept of Practical Work}

According to Woodley (2009), effective practical work can develop important skills in understanding the process of scientific investigation, and can also develop students' grasp of concepts. Similarly, Scanlon, Morris, Di Paolo and Cooper (2002) believe that practical work has an obvious effect on 
students' academic achievement. Although challenging, effect of practical activities build a bridge between hands-on and minds-on activities (Woodley, 2009). Abrahams and Millar (2008) suggest that the minds-on aspects of practical work must be increased in order to make it more effective in developing students' understanding of scientific ideas. Science Community Representing Education [SCORE] (2009) also looked at practical work in science as a 'hands-on learning experience which prompts thinking about the world in which we live'. Practical work in this sense includes fieldwork, laboratory work and experimental work. However, in the context of this study, classroom teaching is the focus but not fieldwork; hence the wordings of 'practical work', 'laboratory work' and 'experimental work' will be used interchangeably to have similar meaning to minds-on and hands-on learning.

During practical work, students are allowed to interact with materials and to check and observe phenomena in a laboratory. The study by Sabri and Emaus (1999) revealed that there is a strong positive relationship between the total number of science practical work conducted in secondary schools and the academic achievement of Palestinian students in science theory and practical courses. The study further indicated that the size of this effect ranged between $26 \%$ and $50 \%$ for various science courses. In that same study, it was revealed that the use of laboratory work helped to develop scientific attitudes in the students, which improved their learning of Chemistry, and also, the students developed scientific skills for problem solving.

Students' practical activities should be designed to develop 'higher' cognitive skills that underpin scientific methods of working (Ng \& Nguyen, 2006). The intended learning outcomes of carrying out practical work must be made clear in students' minds so that students will not be confused with the complexity of the practical task while carrying it out (Brownell \& Kloser, 2015). The practical work should be well designed and in-depth to help students acquire and develop the intended scientific concepts (Bernholt, Broman, Siebert, \& Parchmann, 2019). However, research has shown that most practical work in science laboratory manuals are prescriptive, providing little or no opportunities for open-ended learning and that practical work can be unproductive and little learning of science goes on with students in practical classes (Singer \& Smith, 2013; Sumarni, Wardani, Sudarmin, \& Gupitasari, 2016). This confirms the findings of Usman (2010) who revealed that there was no significant difference in academic achievement of students with practical work and those without practical work in integrated science lessons. Another study by Lunetta (2008) and Abrahams (2009) challenged the long-held notion that practical work offered students a more realistic experience in science and provided learners with motivation.

\section{Scientific Process Skills to be developed for Practical Work}

In a broader sense, scientific process skills may be referred to as diverse ways in which scientists study the natural world, propose ideas, explain and justify assertions based upon evidence derived from scientific work. In Ghana, the Physics teaching and learning syllabus (MoESS, 2010), specifies the practical skills to be assessed by providing generic marking schemes for assessing the Physics practical examination papers. This pre-supposed that students needed to acquire certain specific skills before they could respond effectively to the tasks contained in the test items of the practical examination papers. The marking schemes divided the practical skills to be acquired into broad areas and these included planning, manipulation of equipment, measurement and observation, presentation of data and observation, analysis, conclusion and evaluation.

This study addressed skills to be acquired by students under the following seven headings that contribute to the overall understanding of scientific methodology: (1) planning the experiment, (2) setting up and manipulating apparatus, (3) making measurement and observations, (4) recording and presenting observations and data, (5) analyzing data and drawing conclusions, (6) evaluating procedures and (7) evaluating conclusion (SCORE, 2009).

\section{Attitude of Students towards Practical-based Teaching and Learning of Science}

Students' attitudes towards particular disciplines affect their learning and level of achievement in the discipline. According to Partin and Haney (2012), inherent attitudes such as interests, beliefs, confidence and self-efficacy, may impact how students approach learning, such as, problemsolving strategies, study habits and critical thinking with that discipline. Science practical activities have been endorsed for its role in ensuring positive student attitudes about science and developing students' interest in science and ability to use equipment. Sneddon, Slaughter and Reid (2009) 
found that university students in Scotland felt that laboratory work improved their practical skills and their ability to understand theory. A study by Kim and Chin (2011) reported that practical work was a significant tool for developing students' scientific knowledge and habit of mind. Toplis and Allen (2012) also indicated that practical work forms an integral part in ensuring that learners' in-depth understanding of content during the formative years of secondary school science learning is enhanced. A study by Glasman and Albarracin (2006) also indicated that a major reason why it is important to develop students' positive attitudes towards science is that attitude predicts behavior.

\section{Empirical Studies on Practical Work}

A survey conducted by NESTA indicated that $99 \%$ of the sample of science teachers believed that enquiry learning had an impact on students' performance and attainment (NESTA, 2005). According to Hofstein and Mamlok (2007), practical work, when well organized, can increase students' sense of ownership of their learning and can increase their motivation. They further revealed that, substantial evidence exists to indicate that laboratory work, when properly conceived, adequately planned, well taught and effectively followed up, offers learners opportunities to develop their knowledge and skills in ways that add value to their everyday experiences in the classroom. Talisayon (2006) also found out that learners developed improved attitudes towards science as a result of practical courses. Luketic and Dolan (2013) assert that practical activities foster positive attitudes and interest in science. Practical work provides motivational benefits such as interest and enjoyment, development of skills and science knowledge, learning about scientific method and developing scientific attitudes. However, there is also evidence from other research studies that practical work has no impact on students' achievement in science (Usman, 2010; Abrahams, 2009; Lunetta, 2008). Hence, an investigation into the effect of practical work on learners' academic achievement is worth pursuing.

\section{Research Methodology}

This section presents the methodology used to conduct the study. It includes the research design, population and sampling procedures, research instruments, validity and reliability of research instruments, data collection and data analysis procedures.

\section{Research Design}

The study employed an action research design, which describes the process of systematic inquiry that studies a school situation to understand and improve quality of the educative process (Johnson, 2012). This design was appropriate to help determine how inculcating practical work in the teaching and learning of selected concepts in electricity would impact students' academic achievement, their acquisition of scientific skills as well as their attitude towards the study of Physics.

\section{Population and Sampling}

The target population for this study was one hundred and two (102) science students in a selected Senior High Technical School in the Kwaebibirem Municipal in the Eastern Region of Ghana. Purposive sampling technique was used to select a second-year science class which was made up of fifty (50) students. Second year students in senior high schools in Ghana are between the age ranges of $16-20$ years. This year group was chosen based on the fact that they had already spent a little over a year in the school, and as such, had been introduced to some basic scientific process skills. They had also learnt some fundamental principles in Physics (especially in electricity) in first year, and also, not being in the final year (year three), were not under any pressure to write external examination.

\section{Research Instruments}

The research instruments used to collect data were a student learning evaluation form as appears in table 1 and a questionnaire which were selfconstructed by the researchers.

Table 1: Student Learning Evaluation Form

\begin{tabular}{ll}
\hline Degree of Acquisition & Criteria for Scoring \\
\hline No Skill & $\begin{array}{l}\text { Blank space, unclear responses. } \\
\text { Responses that demonstrated } \\
\text { acquisition of some of the skills. } \\
\text { Responses that contain all parts } \\
\text { of scientific process skills. }\end{array}$ \\
\hline
\end{tabular}

\section{Student Learning Evaluation Form}

The Student Learning Evaluation Form collected data on the performance of students at the first three phases of the study. The form consisted of the criteria on which students' responses to given tasks in the pre-intervention test, weekly intervention exercises and post-intervention test were examined. Responses were evaluated to determine whether they satisfied the requirements of the tests. 


\section{Questionnaire}

The questionnaire designed for this study involved items meant to assess the students' attitude towards the study of selected concepts in electricity using practical activities. The questions were based on four main thematic areas, which were:

1. Ability to understand the concept learnt (A)

2. Ability to arouse and maintain interest in lesson (B)

3. Ability to communicate and interpret results (C)

4. Ability to relate concept learnt to everyday life activities (D)

It involved closed ended items on a five-point Likert scale rated in the range Strongly Disagree (1), Disagree (2), Neutral (3), Agree (4) and Strongly Agree (5).

\section{Validity and Reliability}

Both research instruments were given to some experienced colleagues for review to eliminate biased constructs and ambiguous items in order to ensure content validity, accuracy and appropriate format. To determine the reliability, the instruments were field pilot-tested at a different Senior High School located at the Kwaebibirem Municipal of the Eastern Region with similar characteristics to the school where the research was conducted. Selected science students answered the questions and based on the responses, an Alpha Cronbach value of 0.80 was obtained, meaning there was high correlation of each test item with the total score test.

\section{Data Collection Procedures}

This study involved Pre-intervention phase, Intervention phase and Post-intervention phase.

\section{Phase 1: Pre-Intervention Phase}

The pre-intervention phase, which took place during the first 30 minutes of each lesson, was carried out to ascertain the students' level of acquisition of basic laboratory practical skills acquired from the previous practical lesson. The students were given practical tasks based on the skills learnt during a previous lesson, and were allowed to demonstrate the skills learnt by performance of hands-on practical activities. These activities included manipulating and setting up of apparatus and instruments, measuring physical quantities with various instruments and presenting results in tables and graphs. The students' performance during the hands-on activities was then evaluated using the Student Learning Evaluation Form. The researchers recorded the scores obtained by each student as his/her pre-test score.

\section{Phase 2: Intervention Phase}

At the second phase, the researchers taught some selected concepts in electricity for six weeks focusing on the laboratory process skills to be achieved. Each of the six lessons was imbued with laboratory practical exercises using a combination of demonstrations and group work. Students were guided to perform laboratory practical experiments both in groups and on their own. The practical exercises in each of the six weeks were constructed based on the skills developed within the week and that of the previous weeks, and each lasted 90 minutes. Responses were marked and the marked scripts distributed to students before the next exercise. Descriptive feedback was provided on each wrong response provided by students. This was done to enable students identify specific strengths and area needing improvement. General discussion on the feedbacks was done after the distribution of the marked scripts. Weakness and misrepresentation of skills were addressed. A sample of the rubrics for the practical work (Task), which was used for all the lessons and the method for scoring are presented below:

\section{Task}

You are provided with a potentiometer, an accumulator, a standard resistor, an ammeter, a plug key and a jockey. Set up the circuit as shown in Figure 1. Close the key and use the jockey to make contact with the potentiometer wire such that $L=$ $20 \mathrm{~cm}$. Record the ammeter reading I. Calculate the reciprocal $\mathrm{I}^{-1}$. Repeat the procedure for values of $\mathrm{L}=$ $30 \mathrm{~cm}, 40 \mathrm{~cm}, 50 \mathrm{~cm}, 60 \mathrm{~cm}$ and $70 \mathrm{~cm}$. Tabulate your readings. Plot a graph with $\mathrm{I}^{-1}$ as ordinate and $\mathrm{L}$ as abscissa. Draw a straight line through your points and extend it to meet the vertical axis. Calculate the slope of your graph and read off the value of $\mathrm{I}^{-1}$ when $L=0$.

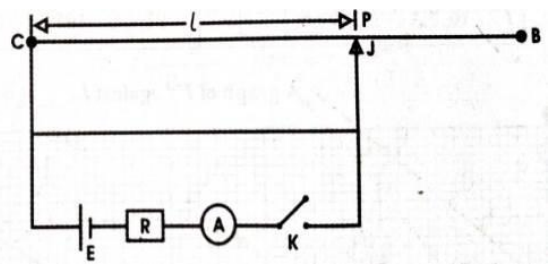

Scoring procedure

Figure 1: Sample Electrical Circuit Showing Potentiometer and Ammeter 
To demonstrate "correct skills" for setting up the circuit as demanded by the task, the respondent should be able to close the key and use the jockey to make contact with the potentiometer, read and record the ammeter reading $\mathrm{I}$, calculate the reciprocal $\mathrm{I}^{-1}$ and repeat the procedure for different lengths of the potentiometer wire and tabulate their readings. Other skills and competencies including being able to choose the right scale to plot the graph, draw a straight line through the points and extend it to meet the vertical axis, calculate the slope of the graph and read off the value of $\mathrm{I}^{-1}$ when $L=0$. The responses were classified as "partial skills" if respondents were able to exhibit some skills and competencies but not others. Finally, responses were classified as "no skills" if respondents could not set up the apparatus for the experiment and failed to present any meaningful responses or left the spaces blank (Table 1).

\section{Phase 3: Post- Intervention Phase}

The post-intervention phase of the study involved monitoring the effects of the intervention strategies on the acquisition and development of requisite scientific process skills by the students and evaluation of the intervention strategies. This was done by monitoring each student's work output at the end of each week. The student's output was monitored by the researchers based on his/her responses to the tasks of the week using the student learning evaluation form (Table 1). The responses were judged by whether they addressed the expected outcome and reflected acquisition of skills taught. The score obtained by the students during this phase was designated as post-intervention test scores.

At the end of the last week, a questionnaire was administered to gather information on students' attitude towards the study of some selected topics in electricity using practical activities. A five-point Likert scale was used to obtain data. The students responded to items in the questionnaire under four main thematic areas, which were, Ability to understand the topic taught, Ability to arouse and maintain interest, Ability to communicate and interpret results and Ability to relate taught concept to everyday life activities.

On the Likert scale, scores of 4 and 5 were considered as high scores whereas 1 and 2 were designated low scores. A score of 3 indicated an average score, interpreted as being neutral about the concerned attitudinal attribute.

\section{Data Analysis Procedures}

Data from the pre-intervention exercises, students' output in the weekly intervention exercises and post-intervention exercises were analysed qualitatively and quantitatively using descriptive statistics to determine whether they reflected correct acquisition of skills learnt and consequently, academic performance.

Qualitatively, responses with correct explanations showing the development of the needed process skills were classified "correct skills". Responses that were related to the questions but with incorrect demonstration of the needed process skills were classified as "partial skills" and the responses that did not relate to the question and not demonstrate the needed process skills were classified as "no skills." These categories of evaluation schemes used to measure students' level of skills acquisition are indicated in Table 1.

Data from the questionnaire was also analysed quantitatively to determine whether students exhibited positive attitudes towards the use of practical work in the learning of electricity. The results from these analyses were expressed in percentages and tabulated. The data was then subjected to descriptive analysis with the aid of Microsoft Excel 2010 Computer Software.

\section{Results and Discussion}

This section presents results obtained and discusses findings along the research questions.

Research question 1: How do the academic achievements of students compare, before and after using practical work to teach selected topics in electricity?

The students' levels of acquisition of skills and competencies and hence their academic achievement during the pre-intervention phase were recorded and analysed using the student learning evaluation form. This was done by evaluating students' acquisition of skills in manipulating equipment and apparatus, as well as their exhibition of scientific process skills during the pre- intervention exercises as in in Table 2.

Table 2: Responses to Pre-Intervention Exercises

\begin{tabular}{lcc}
\hline \multicolumn{1}{c}{ Skills } & Frequency & Percent \\
\hline Correct Skills & 2 & 4 \\
Partial Skills & 15 & 30 \\
No Skills & 33 & 66 \\
Total & $\mathbf{5 0}$ & $\mathbf{1 0 0}$ \\
\hline
\end{tabular}


Data from Table 2 shows that most of the skills and competencies exhibited by the students did not reflect correct skills needed for Physics practical work. Two (2) students representing $4.0 \%$ were able to set up the apparatus for the experiment correctly as expected, and also exhibited competent scientific skills in carrying out the laboratory practical work. Fifteen (15) students representing 30.0\% exhibited partial skills while thirty-three (33) students representing $66.0 \%$ could not set up the apparatus for the experiment and failed to present any meaningful response or left the space blank. This indicates that majority of the students (48) representing $96.0 \%$ did not correctly exhibit any of the scientific skills required for practical work.

Data was collected on the students' output in all the weekly practical lessons during the intervention phase. Results from these exercises are presented in Table 3 to 7 .

The task for week one followed the sample rubrics described above, and the main objective was for the students to set up given apparatus and manipulate them to obtain results.

Table 3: Analysis of Students Responses to Task 1 of Week One

\begin{tabular}{lll}
\hline Level of Skill Acquisition & Frequency & Percentage (\%) \\
\hline Correct Skills & 40 & 80.0 \\
Partial Skills & 7 & 14.0 \\
No Skills & 3 & 6.0 \\
\hline Total & $\mathbf{5 0}$ & $\mathbf{1 0 0 . 0}$ \\
\hline
\end{tabular}

Table 4: Analysis of Students Responses to the Task of Week Two

\begin{tabular}{lll}
\hline Level of Skill Acquisition & Frequency & Percentage (\%) \\
\hline Correct Skills & 44 & 88.0 \\
Partial Skills & 4 & 8.0 \\
No Skills & 2 & 4.0 \\
\hline Total & $\mathbf{5 0}$ & $\mathbf{1 0 0 . 0}$ \\
\hline
\end{tabular}

Table 5: Analysis of Students Responses to Task of Week Three

\begin{tabular}{lll}
\hline Level of Skill Acquisition & Frequency & Percentage (\%) \\
\hline Correct Skills & 47 & 94.0 \\
Partial Skills & 3 & 6.0 \\
No Skills & 0 & 0.0 \\
\hline Total & $\mathbf{5 0}$ & $\mathbf{1 0 0 . 0}$ \\
\hline
\end{tabular}

Data from Table 3 indicated that as many as forty (40) students representing $80.0 \%$ were able to set up the experiment as required by the question and also manipulate them to obtain the expected results. Seven (7) students representing $14.0 \%$ were able to set up the apparatus as required but failed to manipulate the apparatus to obtain results, and three (3) students representing $6.0 \%$ failed on both assignments.

Week two required the students to set up given apparatus as shown in a given figure, manipulate the apparatus by following the given rubrics and tabulate the results obtained using a given table.

From Table 4, forty-four (44) students representing $88.0 \%$ were able to accomplish all the tasks as expected of them correctly, four (4) students representing $8.0 \%$ exhibited partial skills as they were able to perform some of the tasks but not others, and two (2) students representing 4.0\% showed 'no skills.'
In week three, the students were to carry out an experiment by following a set of instructions to determine the resistivity of a given wire using a set of given apparatus. Table 5 shows forty-seven (47) students representing $94.0 \%$ being able to set up the apparatus as required, manipulating the apparatus correctly to obtain the results as expected. Three (3) of the students representing $6.0 \%$ were able to exhibit partial skills in obtaining the results and no student had his/her response classified as no skills.

In weeks four and five, the students were taken through practical graph lessons. In both weeks, they were tasked to set up given apparatus to determine the resistivity of a given wire and use the data obtained to plot a graph. They were also to determine the slope and intercepts of the graph, and interpret the solutions obtained in relation to resistivity of the given wire. 
Data from Table 6 indicated that majority of the student demonstrated some high level of acquisition of skills for the setting up of the apparatus, manipulation and the graph work. Forty-five (45) students representing $90 \%$ were able to set up the apparatus as required by the question, measure, record and tabulate their results correctly. They were also able to correctly plot the graph, determine the slope and intercept as well as interpret the obtained results correctly. Five (5) students representing $10.0 \%$ were able to set up the apparatus, measure and record the value, tabulate their results and plot the graph correctly, but failed to find the slope of the graph as well as the intercept. These constituted partial skills.

Table 7 showed that every student demonstrated some level of acquisition of skills for graph work. Forty-six (46) students representing 92\% showed mastery over the tasks by exhibiting correct skills while only four (4) students representing $8.0 \%$ showed partial skills.

Table 6: Analysis of Students Responses to Task of Week Four

\begin{tabular}{lll}
\hline Level of Skill Acquisition & Frequency & Percentage (\%) \\
\hline Correct Skills & 45 & 90.0 \\
Partial Skills & 5 & 10.0 \\
No Skills & 0 & 0.0 \\
\hline Total & $\mathbf{5 0}$ & $\mathbf{1 0 0 . 0}$ \\
\hline
\end{tabular}

Table 7: Analysis of Students Responses to Task of Week Five Lesson

\begin{tabular}{lll}
\hline Level of Skill Acquisition & Frequency & Percentage (\%) \\
\hline Correct Skills & 46 & 92.0 \\
Partial Skills & 4 & 8.0 \\
No Skills & 0 & 0.0 \\
\hline Total & $\mathbf{5 0}$ & $\mathbf{1 0 0 . 0}$ \\
\hline
\end{tabular}

Table 8: Analysis of Students Responses to Post-Intervention Exercises

\begin{tabular}{lll}
\hline Level of Skill Acquisition & Frequency & Percentage (\%) \\
\hline Correct Skills & 47 & 94.0 \\
Partial Skills & 3 & 6.0 \\
No Skills & 0 & 0.0 \\
\hline Total & $\mathbf{5 0}$ & $\mathbf{1 0 0 . 0}$ \\
\hline
\end{tabular}

Table 9: Average Score Obtained by Students for Pre-test and Post-test Intervention Tests

\begin{tabular}{ll}
\hline Test & Average Score (\%) \\
\hline Pre-intervention Test & 39.72 \\
Post-intervention Test & 79.92 \\
\hline
\end{tabular}

At the end of the intervention period, the students were taken through a post-intervention exercise. This exercise took one week after the intervention period. The aim of this exercise was to evaluate the effect of the intervention strategy implemented on the students' academic achievement in some selected topics in electricity. Data collected on students' output in the post-test were recorded and analysed in Table 8.

Table 8 reveals that none of the students had their responses classified as no skills. Thus, forty-seven of the respondents representing $94.0 \%$ demonstrated correct skills whilst only three of the respondents representing $6.0 \%$ responses showed partial skills for practical work in some selected topics in electricity. All the students could demonstrate some scientific skills and competencies required for science practical work.

The mean score obtained by each student for all the six lessons was calculated for both pre-intervention exercises and post-intervention exercises. Hence the overall score obtained by each student for the preintervention and post-intervention tests were recorded and the means for both exercises calculated. The result is presented in Table 9.

Data from Table 9 shows that the average score of the students' overall pre-test scores was 39.72\%, whilst that of their post-test scores was $79.92 \%$.

The students' progress in acquiring the requisite scientific skills and competencies needed for practical work was recorded over the intervention 
period. The number of students that were observed to be making progress in acquiring the skills and competencies throughout the intervention period was recorded on a weekly basis. The researchers tabulated these acquired skills in Table 10.
Data obtained from Table 10 and Figure 2 indicates that there was a steady increase in the number of students observed to be acquiring scientific skills. At the end of the $6^{\text {th }}$ week, over $90 \%$ of students had acquired the requisite skills and also demonstrated correct competencies needed for practical work.

Table 10: Science Process Skills Acquired Through Practical Work

\begin{tabular}{lcccccc}
\hline Required Skills & \multicolumn{2}{c}{ Skills Acquired Weekly by Students } & \multicolumn{2}{c}{} \\
& Week & Week & Week & Week & Week & Week \\
& $\mathbf{1}$ & $\mathbf{2}$ & $\mathbf{3}$ & $\mathbf{4}$ & $\mathbf{5}$ & $\mathbf{6}$ \\
\hline Setting up of apparatus & 15 & 20 & 27 & 38 & 40 & 48 \\
Applying right materials /equipment & 17 & 21 & 25 & 36 & 37 & 49 \\
& & & & & & \\
Following experimental procedure & 11 & 20 & 27 & 33 & 33 & 47 \\
& & & & & & \\
Labelling of diagrams & 14 & 25 & 32 & 39 & 41 & 47 \\
Reading of instruments & 13 & 20 & 28 & 32 & 45 & 45 \\
Measuring correctly & 15 & 19 & 20 & 28 & 44 & 46 \\
Using correct units & 17 & 24 & 36 & 40 & 41 & 49 \\
Choosing correct scale & 4 & 15 & 20 & 28 & 35 & 45 \\
Plotting of graph & 12 & 14 & 18 & 25 & 37 & 43 \\
Analysing data correctly & 10 & 18 & 20 & 25 & 38 & 42 \\
Interpreting results correctly & 14 & 18 & 21 & 24 & 39 & 43 \\
\hline
\end{tabular}

Figure 2: Science Process Skills Acquired Through Practical Work

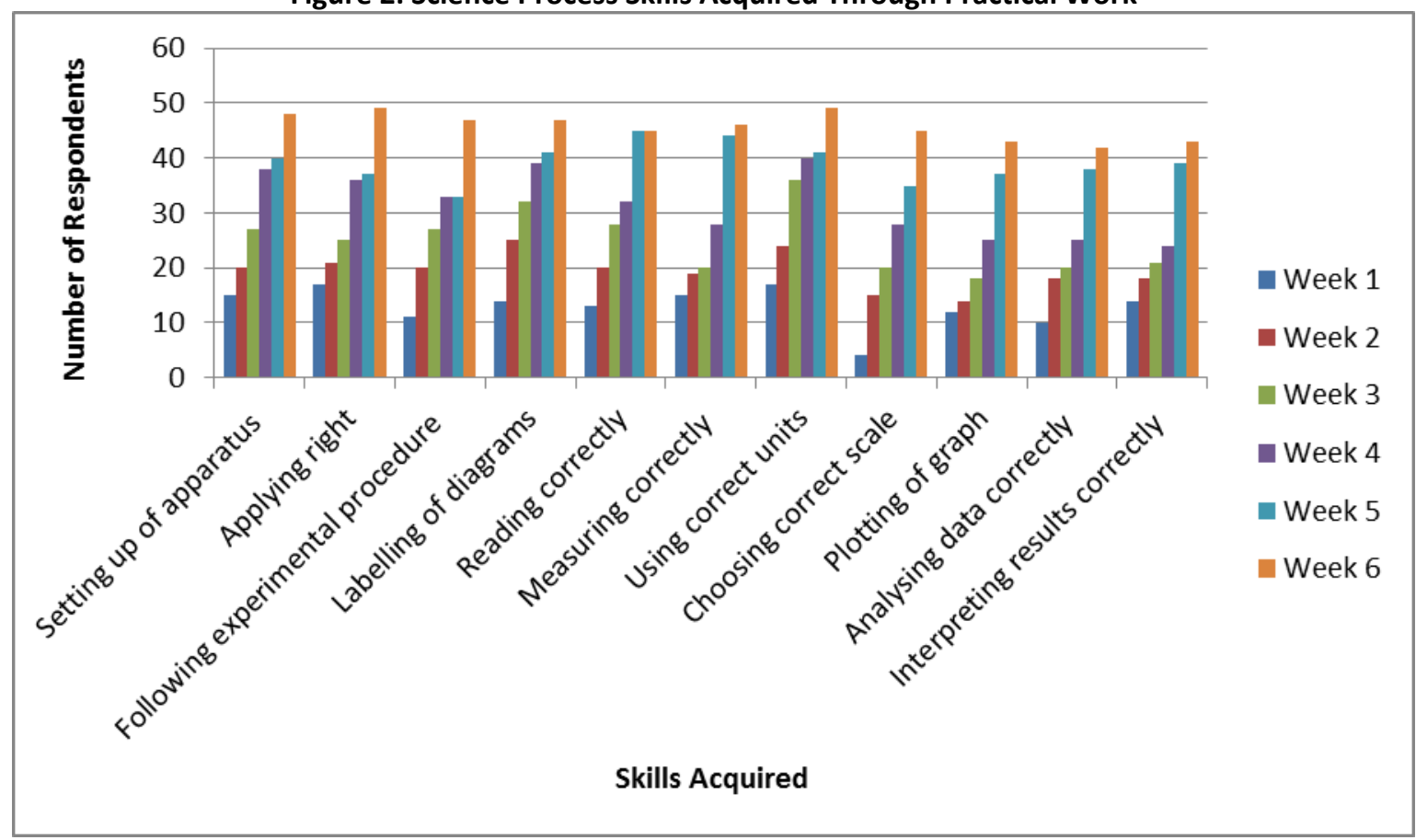

Analysis of data from Table 2 revealed that before the intervention, most of the responses from the students to the pre-test items was incorrect and did not demonstrate correct scientific skills needed for practical work in some selected concepts in electricity. Majority of the students (96\%) could not demonstrate the correct scientific process skills needed for practical work. These were indications that students had not yet developed the conceptual understanding needed for excelling in practical work in some selected concepts in electricity. However, results from Tables $3-8$ revealed that as the students were exposed to laboratory practical work and remediation during the intervention, their 
scientific process skills improved tremendously. At the end of the intervention, majority of the students (94\%) exhibited correct skills needed for scientific practical work, implying that they had mastery of theses scientific skills needed to excel in their learning of Physics. Indications from Table 10 and Figure 2 were that there were significant improvements in the students' level of acquisition of science process skills over the period of intervention. This is evident that the intervention strategy adopted (practical work) had improved the ability of the students to acquire requisite scientific process skills needed for practical work in Physics. This is in congruence with the findings of the study by Kim and Chin (2011), who indicated that practical work was a significant tool for developing students' scientific knowledge and habit of mind, and therefore offered students a more realistic experience in science and provided learners with motivation.

Results from Table 9 revealed that the average score for the students before the intervention strategy was $39.72 \%$, which was quite low and did not express a strong academic achievement. However, after the use of the intervention, it was realized that the mean academic achievement of the same students in the post intervention test had increased to $79.92 \%$. This indicated that using practical work in teaching some selected concepts in electricity had a greater advantage of enhancing students' academic achievement and retention of the concepts taught. The findings buttressed the conclusion by Sabri and Emuas (1999) that there was a strong relationship between the total number of secondary science practical work in secondary schools and their academic achievements.

Research Question 2: To what extent does the use of practical work affect students' attitude towards the study of some selected concepts in electricity?

This question sought to find out how the use of practical work in the study of selected concepts in electricity impacted the students' attitudes towards learning the concepts and physics in general.

There were four main thematic areas on which the items were based, which were:

- Ability to understand the concept learnt (A)

- Ability to arouse and maintain interest in lesson (B)

- Ability to communicate and interpret results ( C)

- Ability to relate concept learnt to everyday life activities (D)

Table 11 shows the frequency $(\mathrm{N})$ and percentages (\%) of students' responses to the questionnaire.

Table 11: Students' Responses on Investigated Attitudes

\begin{tabular}{cccccccc}
\hline Investigated Item & \multicolumn{2}{c}{ High } & \multicolumn{2}{c}{ Neutral } & \multicolumn{2}{c}{ Low } \\
& $\mathbf{N}$ & $\%$ & N, & $\%$ & N & $\%$ \\
\hline A & 45 & 90 & 4 & 8 & 1 & 2 \\
B & 47 & 94 & 1 & 2 & 2 & 4 \\
C & 40 & 80 & 6 & 12 & 4 & 8 \\
D & 32 & 64 & 10 & 20 & 8 & 16 \\
\hline
\end{tabular}

Data from Table 11 depicts that each of the four themes had a high number of positive responses from the participants. Concern B (Ability to arouse and maintain interest) received the highest positive responses with 47 students representing 94\% indicating that they had received a boost in interest in practical work. However, the same could not be observed about concern $\mathrm{D}$ (Ability to relate taught concept to everyday life), which had only 32 students representing $64 \%$ responding positively to it.

The results indicated that the students demonstrated positive attitudes towards the study of the selected topics in electricity as a result of the practical based instruction. The number of students who indicated high responses to all the four attitudinal concerns was greater than the other responses of neutral and low. This depicts that over $90 \%$ of the students had developed positive attitudes towards the learning of selected concepts in electricity. The responses indicated that $90 \%$ responded positively that they understood concepts taught, 94\% indicated that their interests in the practical lessons were aroused and these interests were sustained throughout the period of the intervention, $80 \%$ of the students could interpret results obtained as well as communicate the results and $64 \%$ could apply concepts learnt to everyday phenomena. These findings tend to agree with Talisayon (2006) who found out those learners developed improved attitudes towards science as a result of practical courses. The result is also in 
congruence with Toplis and Allen's (2012) study in which they suggested that practical work forms an integral part in ensuring that learners' in-depth understanding of content during the formative years of secondary school science learning is enhanced.

\section{Conclusions and Recommendations}

This section provides the conclusions and then gives the recommendations.

\section{Conclusion}

The study concluded that practical work helped to enhance the academic achievement of students in selected concepts in electricity. This is indicated in the fact that students' average academic achievement after the inculcation of practical work was higher than the students' average academic performance before the introduction of frequent practical work. The students' level of acquisition of the requisite scientific process skills needed for science practical work was greatly enhanced during the implementation of the intervention strategies of the study. Following these stated achievements, the students' attitudes towards the study of Physics was evidently improved with majority of the students exhibiting positive attitudes towards the study of the subject.

\section{Recommendations}

The study recommended that it would be necessary for physics teachers to adopt the use of practical work as a technique in teaching so as to solve the problem of many students under-performing in Physics at the senior high school level. Since the use of practical work in teaching has the ability to raise and maintain students' interest, develop their science process skills and improve their academic achievement, teachers are encouraged to teach concepts alongside with practical activities. Students should be given the chance to practice the science process skills acquired through practical work regularly to enable them carry out practical work successfully on their own.

\section{References}

Abrahams, I. (2009). Does practical work really motivate? A study of the affective value of practical work in secondary school science. International Journal of Science Education, 31(17), 2335-2353.

Abrahams, I., \& Millar, R. (2008). Does practical work really work? A study of the effectiveness of practical work as a teaching and learning method in school science.
International Journal of Science Education, 13(14), 1945-1969.

Alkan, F. (2016). Experiential Learning: Its Effects on Achievement and Scientific Process Skills. Journal of Turkish Science Education, 13(2), 45-90.

Al-Rawi, I. (2013). Teaching methodology and its effects on quality learning. Journal of Education and Practice, 4(6), 100-105.

Babalola, F., Lambourne, R., \& Swithenby, S. (2020). The Real Aims that Shape the Teaching of Practical Physics in Sub-Saharan Africa. Int J of Sci and Math Educ , 18, 259-278.

Bernholt, S., Broman, K., Siebert, S., \& Parchmann, I. (2019). Digitising Teaching and LearningAdditional Perspectives for Chemistry Education. Israel Journal of Chemistry, 59(6), 554-564.

Brownell, S. E., \& Kloser, M. J. (2015). Toward a conceptual framework for measuring the effectiveness of course-based undergraduate research experiences in undergraduate biology. Studies inHigher Education, 40(3), 525-544.

Duniya, J. N. (2009). Efficacy of Indoor and Outdoor Laboratory Approaches on Acquisition of Science Process Skills and Performance among Biology, Polytechnics Students. Seminar paper presented in Science Education Department of Education. A. B. U. Zaria, Nigeria.

Glasman, L. R., \& Albarracin, D. (2006). Forming attitudes that predict future behaviour: $A$ meta-analysis of the attitude-behaviour relation. Psychological bulletin, 132(5), 7078.

Hofstein, A., \& Mamlok, R. (2007). The laboratory in science education: the state of the art. Chemistry education research and practice, 8(2), 105-107.

Johnson, A. P. (2012). A short guide to action research (4th ed.). New Jersey: Pearson Education.

Josiah, M. M. (2013). Effects of Practical Physics Knowledge on Students' Academic Achievement: A Study of Pankshin Local Government Area of Plateau State, Nigeria. World Educators Forum, 2(1), 1-9. 
Kim, M., \& Chin, C. (2011). Pre-service teachers' view on practical work with orientation in textbook-oriented science classrooms. International Journal of Environmental Science Education, 6(1), 23-37.

Luketic, C., \& Dolan, E. (2013). Factors influencing students' perception of high school science laboratory environment. Learning Environment Research, 16(4), 37-47.

Lunetta, V. N. (2008). Learning and teaching in the school science laboratory: An analysis of research, theory, and practice. Handbook of research on science education, 2(3), 25-30.

Mankilik, M. (2011). Practical Approaches to the teaching of science. In A keynote address delivered at the workshop organised by School of Sciences, Federal College of Education. Pankshin: Nigeria.

Masingila, J., \& Gathumbi, A. W. (2012). A collaborative project to build capacity Through Quality Teacher preparation.

Millar, R. (2008). Action Research: A guide for the teacher researcher (2nd ed). Boston: Person Education.

Millar, R. (2010). Practical work. In J. Dillion \& J. Osborne (Eds.), Good practice in science teaching: What research has to say (2nd ed., pp. 108-134). London, England: McGrawHill.

MoESS. (2010). Teaching syllabus for Physics (Senior High Schools). Accra-Ghana.

NESTA. (2005). Coherence of the knowledge base and the firm's innovative performance: evidence from the US pharmaceutical industry. The Journal of Industrial Economics, 53(1), 123-142.

Ng, W., \& Nguyen, V. T. (2006). Investigating the Integration of Everyday Phenomena and Practical Work in Physics Teaching in Vietnamese High Schools., 7(1), 36-50. International Education Journal, 7(1), 36-50.

Olubu, O. M. (2005). Influence of Laboratory Learning Environment on Students' Academic Performance in Secondary School Chemistry. Us-China Education Review, 5(12), 814-821.
Partin, M. L., \& Haney, J. J. (2012). The CLEM model: Path analysis of the mediating effects of attitudes and motivational beliefs on the relationship between perceived learning environment and course performance in an undergraduate non-major biology course . Learning Environments Research, 15(1), 103123.

Sabri, K. S. \& Emuas, A. H. M. (1999) The relationship between school laboratory experiments and academic achievement of Palestinian students in introductory university science courses, Research in PostCompulsory Education, 4:1, 87-96, DOI: 10.1080/13596749900200047.

Scanlon, E., Morris, E., Di Paolo, T., \& Cooper, M. (2002). Contemporary approaches to learning science: technologically-mediated practical work.

SCORE. (2009). Practical work in science. A report and proposal for a strategic framework. Retrieved August 25, 2020, from www.scoreeducation.org/ downloads/ practicalwork1report.pdf.DCSF, London.

Singer, S., \& Smith, K. A. (2013). Discipline-based education research: Understanding and improving learning in undergraduate science and engineering. Journal of Engineering Education, 102(4), 468-471.

Sneddon, P. H., Slaughter, K. A., \& Reid, N. (2009). Perceptions, views and opinions of university students about physics learning during practical work at school. European Journal of Physics, 30(5), 11-19.

Sumarni, W., Wardani, S., Sudarmin, S., \& Gupitasari, D. N. (2016). Project based learning (pbl) to improve psychomotor skills: a classroom action research . Journal Pendidikan IPA Indonesia, 5(2), 157-163.

Talisayon, V. (2006). Science-Related Attitudes and Interest of Students. Paper presented in the IOSTE XII Symposium, Penang, Malaysia, August 1- 4.

Toplis, R., \& Allen, M. (2012). I do and I understand: Practical work and laboratory use in United Kingdom schools. Eurasia Journal of Mathematics, Science \& Technology Education, 8(1), 3-9. 
Usman, I. A. (2010). The Effects of Indoor and Outdoor Laboratory Instructional Methods on Academic Achievement of Junior Secondary School Integrated Science Students in Zaria Local Government Area of Kaduna State. Journal of Studies in Science and Mathematics Education, 1(1), 1-5.

WAEC. (2020). Chief Examiner's Reports: Science Program. Accra: WAEC.

WAEC. (2019). Chief Examiner's Reports: Science Program. Accra: WAEC.
WAEC. (2018). Chief Examiner's Reports: Science Program. Accra: WAEC.

WAEC. (2017). Chief Examiner's Reports: Science Program. Accra: WAEC.

WAEC. (2016). Chief Examiner's Reports: Science Program. Accra: WAEC.

WAEC. (2015). Chief Examiner's Reports: Science Program. Accra: WAEC.

Woodley, E. (2009). Practical work in school sciencewhy is it important. . School Science Review, 91(335), 49-51. 